\title{
Doing community geography
}

\author{
Heather Fischer (D) Daniel Block - Amber Bosse - Timothy L. Hawthorne • \\ Jin-Kyu Jung $\cdot$ Hamil Pearsall $\cdot$ Amanda Rees $\cdot$ Jerry Shannon
}

Accepted: 15 June 2021 / Published online: 26 June 2021

(C) The Author(s) 2021

\begin{abstract}
Community Geography offers researchers, community groups, and students opportunities to engage in action oriented applied geographical research. Creating and sustaining these research programs can be challenging, programs can involve many partners from both academic and the community, have different goals and purposes, and utilize a variety of methods to perform research. In this paper we offer a framework of three primary overarching principles for implementing CG projects; (1) Who, (2)
\end{abstract}

H. Fischer $(\bowtie)$

STEM Research Center, Oregon State University, 254 Gilbert Hall, Corvallis, OR 97333, USA

e-mail: Heather.fischer@oregonstate.edu

D. Block

Chicago State University Williams Science Center, Room 3219501 S. Martin Luther King Jr. Drive, Chicago,

IL 60628-1598, USA

\section{A. Bosse}

Department of Geography, University of Kentucky, 817

Patterson Office Tower, Lexington, KY 40506, USA

T. L. Hawthorne

University of Central FL-Sociology, 4297 Andromeda

Loop N.room 403,

Howard Phillips Hall Orlando 32816-1360, USA

J.-K. Jung

University of Washington Bothell, 18115 Campus Way

NE, Box 358530, Bothell, WA 98011-8246, USA
Why, and (3) How. (1) "Who" describes who is involved in CG, including researchers, community partners, academic institutions, (2) "Why" describes the justifications and benefits of taking this approach. (3) "How" explains how CG borrows methodologies from many disciplines within geography and beyond. Our examples are not exhaustive; rather, they serve as starting points to inspire researchers interested in CG.

H. Pearsall

Geography and Urban Studies Department, Temple University, 1115 W. Berks St, Philadelphia,

PA 19122, USA

A. Rees

Department of History and Geography, Columbus State

University, 4225 University Avenue, Columbus,

GA 31907, USA

J. Shannon

Department of Geography, University of Georgia, 210

Field Street, Rm 204, Athens, GA 30602, USA 


\section{Introduction}

Community geography can enable mutually beneficial research and action that empowers communities and affects social change (Hawthorne et al., 2014, 2015; Rees et al., 2020; Robinson, 2010; Robinson \& Hawthorne, 2018; Robinson et al., 2017; Shannon et al., 2020). Doing community geography (CG) can be a complicated process; it generally involves a driver group of stakeholders and uses a mix of qualitative and quantitative methods and various participatory research approaches (Shannon et al., 2020). In this paper, we detangle the complexity of doing a CG project and provide a fundamental guide for implementing such a project from an academic researcher's perspective. ${ }^{1}$ This paper is a part of a larger writing project, including separate pieces focused on the theoretical background and development of a framework around Community Geography (CG) (Shannon et al., 2020) and the pedagogy around teaching CG in the classroom (Rees et al., 2020).

This writing project grew out of recent efforts to define $\mathrm{CG}$ as a form of research praxis and situate it within the larger field of geography. CG draws from pragmatist traditions (i.e., democratic knowledge production coupled with action) in engaged research that is grounded in community engagement and public relevance (Dewey, 2016; Harney et al., 2016; Wills \& Lake, 2020) and from the geographic theorizations of space and place (Shannon et al., 2020). In addition, it is informed by research in Black and feminist geographies that critically examines the positionality of academic geographers and seeks out epistemological stances traditionally marginalized in academic discourse (Eaves, 2017; Haraway, 1988; Pavlovskaya \& St. Martin, 2007). These origins reflect a focus of CG to produce knowledge that is action-focused and centered on public engagement.

The first paper in this writing project (Shannon et al., 2020) provides an extensive review of the background and origins of CG. Shannon et al. (2020) also detangles the theoretical background for CG and offers five characteristics of CG: (1) a focus on place and place-based concerns; (2) diverse positionalities

\footnotetext{
$\overline{1}$ We focus on the academic researcher based on our experiences as academic researchers. We acknowledge the need to produce a guide for community partners and non-academics as well.
}

(3) committed and reciprocal community partnerships; (4) flexible epistemologies and methods; and (5) the use of open research practices and public scholarship. At the same time, Shannon et al. (2020) note limitations to public research traditions that inform CG. Most notably, this includes the problematic elements of the land-grant mission, such as its concentration at historically white universities (Goldstein et al., 2019), as well as the tension between forms of engagement that enhance universities' reputations and emphasize their expertise and those that amplify traditionally excluded voices outside of academia.

The impetus for this paper, in particular, comes from the quick emergence of $\mathrm{CG}$ as a space where academics look to increase public engagement in their work. Funding agencies, such as the National Science Foundation (NSF), increasingly expect funded project teams to engage the public and local communities in their research. ${ }^{2} \mathrm{CG}$ offers a methodological and theoretical framework for projects led by researchers who may not have community engagement experience or community connections. CG also may help crossdisciplinary research teams clarify the contributions a geographical perspective may make on the research and the community. This paper aims to provide researchers interested in CG with an overview of the various stakeholders, outcomes, and methods involved in doing CG.

The five characteristics presented in Shannon et al. (2020) served as the framework for this practical guide. Our guide offers some common aspects of $\mathrm{CG}$ projects and centers on three key principles for implementing CG: (1) Who, (2) Why, and (3) How. (1) "Who" describes who is involved in CG, including researchers, academic institutions, and community and non-academic partnerships. (2) "Why" describes the justifications and benefits of taking this approach for these critical stakeholders. (3) "How" delves into implementing a CG project from project design and methods to sharing outcomes and project evaluation. Our examples are not exhaustive nor prescriptive; instead, they serve as starting points to guide researchers interested in doing CG.

\footnotetext{
${ }^{2}$ The NSF requires grant proposals to address a projects broader impacts, which may include engaging the public in the project or improved well-being of the public (NSF, 2007).
} 


\section{Who}

As mentioned above, a focus on the place, community partners, and diverse positionalities present in a community are part of the five characteristics of CG projects identified by Shannon et al. (2020). Partnerships can take many forms but are characterized by shared power between the partners. For instance, projects may grow out of a community's research priorities or a merging of the researcher's and the community's research priorities (Robinson \& Hawthorne, 2017; Shannon et al., 2020). There is also shared control of the research process and collective ownership over the data and products (Robinson et al., 2017).

As $\mathrm{CG}$ is rooted in longer traditions of public outreach in American higher education (Shannon et al., 2020), many current case studies of CG are between an educational institution (i.e., a university) and one or more community groups or non-profits. While in this paper, many of our examples are from university/community partnerships, CG is not confined to this type of relationship. Projects may also involve government agencies, multiple academic institutions, religious institutions, and even for-profits (Robinson et al., 2017). CG researchers call for increased attention to matters of diversity for the approach, both in terms of participants and setting (see Reflections and Future Directions of Shannon et al., 2020). As such, as CG develops and expands, other configurations of partnerships may become more common. However, the following section speaks to the present moment of CG by discussing the individuals and groups most commonly involved: researchers/research institutions and community members/community groups. This section outlines the typical roles and experiences of each side of these partnerships and describes three main stakeholders and their relationships in CG projects; these include academic researchers, academic institutions, and community and non-academic partners.

Academic researchers and academic institutions

In most cases, $\mathrm{CG}$ includes researchers at institutions of higher education. These are typically faculty members, research staff, or graduate students interested in incorporating CG into their courses and/or their research (for more on pedagogy and CG, see Rees et al., (2020)). Academic researchers engaging in CG often do so because they prioritize pragmatic work, and their research interests are tied to local community interests and are enhanced by community partnerships (Robinson et al., 2017). Research areas such as, but not limited to, food insecurity, public health, social justice, environmental justice, housing, transportation, and urban planning are common topics for CG work (Robinson et al., 2017). Academic researchers may engage in CG individually, through a course or student research project (such as a Research Experience for Undergraduates (REU) project funded by the NSF), or through a formal CG program at their institution (Hawthorne \& Jarrett, 2018).

Academic researchers involved in CG often face the challenge of proving to their institution that their work "counts" for promotion and tenure, especially in research institutions that value peer-reviewed publication and research funding (Center for Urban and Environmental Solutions 2007 cited in Robinson \& Hawthorne, 2018). Many CG projects result in community-facing "deliverables" that are not peer-reviewed academic publications. Even the time that researchers invest in CG to develop relationships can be considered a quantifiable outcome. Some institutions hire faculty with explicit expectations for community-engaged research, such as Syracuse University and the University of Georgia (UGA) (Robinson \& Hawthorne, 2018). At Syracuse University, community members play a role in advising and evaluating the work done by the researcher. At UGA, the $\mathrm{CG}$ position includes a service component missing in other faculty appointments.

CG researchers often rely on institutional support from their academic institutions. This may include monetary support for community-engaged research by sponsoring formal CG programs and centers, faculty positions (like those mentioned above), student research assistantships, or administrative assistance with organizing connections to community organizations. These supports may also parallel the university's mission and, in turn, leverages the university's assets with a broader community and provide technological and resources that the community may not otherwise be privy to (Robinson et al., 2017).

Formal CG programs at universities are generally in the United States (thus, we will focus our discussion on these institutions) and reflect the public engagement focus of the land grant university model (see the 
Public Serving University in Shannon et al., 2020). Many land grant institutions have cooperative extension offices that initially connected local farmers to agricultural research at these universities and expanded to connect the local community to various applied research initiatives at universities (Goldstein et al., 2019). There are many critiques of the land grant model; critics cite land-grant and extension offices as unidirectional, inequitable, and colonialist (10.7 million acres of Indigenous land into college endowments for land grant institutions (High Country News, 2020)). Despite these critiques, this early model of public engagement at universities has influenced how CG programs at universities are formed and operated (Shannon et al., 2020).

CG programs exist at various institutions in the US, from urban and rural based universities and private universities and large public schools. At Chicago State University (CSU), a federally recognized Predominately Black Institution (PBI), for example, the Neighborhood Assistance Center (NAC) (www.csu. edu/nac) works with organizations on Chicago's South Side to develop projects that are community-driven but utilize the expertise of CSU's Geography program and other social sciences. At other academic institutions, researchers have created virtual and physical spaces that serve a similar purpose: Syracuse Community Geography (communitygeography.org), Citizen Science GIS at the University of Central Florida (UCF) (citizensciencegis.org), the Columbus Community Geography Center (https://history. columbusstate.edu/columbuscommunitygeography.

php) at Columbus State University (Georgia), and the Community Mapping Lab at the University of Georgia (UGA) (communitymappinglab.org). However, it should be noted that CSU is also an example of one of the perils of working within university settings. In financial crises or even while administrations change, programs like CG centers can be targets of budget cuts. While the NAC continues to exist, it has gone from having a university-funded director and administrator to being currently unfunded.

Community and other non-academic partners

Many of the non-academic partners in CS programs are non-profit and grassroots community groups. Projects may also involve government agencies, religious institutions, and even for-profits organizations (Robinson et al., 2017). Generally, these partners are providing some kind of service to underserved communities (Robinson et al., 2017). The authors of this paper have personally worked with non-profit community groups such as food banks, social justice organizations, environmental organizations, and public housing and utility assistance programs. Our discussion of non-academic partners in this paper focuses on non-profit community groups because these organizations are the most commonly cited partners for $\mathrm{CG}$ projects. We also focus on the groups as a whole rather than specific individuals in the community because, generally, academic researchers are working with community members through a partnership with a community group.

The needs of these community groups and their reasons for partnering with an academic institution vary. These various needs of the community groups will dictate the nature of the relationship with an academic institution and the group's role in the partnership. Some groups are looking for simple map products of their local area they serve and do not have the resources to create such maps (Robinson et al., 2017). Other groups seek more collaborative partnerships with universities working toward researching a particular issue or developing an ongoing coalition to address systemic problems in the community.

The resources available to these groups also vary widely. Community organizations may lack the resources or capacity to provide robust support to a CG project. Others, however, may be able to offer have physical space, local expertise, and trusting relationships that can all significantly contribute to a project's success. Community groups could also support a CG project financially through providing support for a formal CG program of center or supporting a student worker or intern to work on a CG project. For example, the Knowledge Exchange for Resilience initiative at Arizona State University is funded mainly by its primary community partner, the Virginia G. Piper Charitable Trust.

Relationships between non-academic partners and academic researchers

The various needs of the community partners also dictate the role that the academic researcher and institution will have in the partnership. It is essential to clarify the nature of the relationships and expectations 
from all stakeholders. Researchers and community partners most identify shared interests and co-develop plans to study and address these interests, regardless of how small or simple a project may seem. In other cases, community organizations may lack the resources or capacity to provide such robust support. Yet partnering groups may have physical space, local expertise, and trusting relationships that can all significantly contribute to a project's success.

The initiative called Stabilizing Lives provides an example of the varied roles that partners play in a CG partnership. This initiative involves a partnership with the Atlanta Community Food Bank and researchers at the University of Georgia. Staff at the food bank were aware of persistent levels of food insecurity nationally and within their service area. The food bank staff identified five local food pantries with both capacity and interest in piloting new programming models and an interest in working with clients to collaboratively identify important issues. The food bank had an existing relationship with one of the UGA researchers from a previous research project. Through multiple conversations, UGA faculty and food bank staff developed a mixed-methods, participatory research project that would bring staff, volunteers, and clients together to discuss critical issues shaping the "food worlds" of pantry clients. This partnership was codified in a research plan that articulated the responsibilities and expectations of each partner. The project has resulted in two academic publications (Kurtz et al., 2019; Shannon et al., 2019), and the food bank has also created leadership training for clients due to the results of this research. The food bank provided significant support for this project, including staff time, financial resources, and physical space.

Both university and non-academic groups want to be diligent to avoid establishing partnerships that promote performative or superficial modes of engagement. Since collaborative and participatory methods have become more popular during the past three decades, these methods have sometimes been taken up in exploitative ways (McTaggart, 1991). This exploitation functions in multiple registrars: crowdharvesting (Breen et al., 2015) and mainstreaming (Elwood, 2006) are two examples. Crowd-harvesting frames participants as sources of data production or extraction, not collaborators or co-producers. Therefore, it is more easily identifiable as a form of engagement that is not intended to address the participants' needs.

Meanwhile, mainstreaming is more challenging to identify as it often takes place in settings that, at first glance, appear to be serving community needs. However, a closer examination reveals that rather than challenging ingrained power structures, mainstreamed metrics of participation reify such power structures. The foundation of CG requires that all those who come to the work do so through reflexive and intersectional approaches that, ultimately, challenge traditional conceptualizations of knowledge production and center traditionally excluded perspectives (Shannon et al., 2020). As such, CG provides a framework to critically examine the intentions of the "who" before or throughout the duration of the partnership, providing grounds to resist establishing partnerships or discontinuing established partnerships that do not meet the commitments of community geography.

\section{Why}

Mutual understanding is a beneficial outcome for all stakeholders of a CG program. Since much of this work is done in local communities, it takes faculty, staff, and students out of the walls of the "ivory tower." It places them in neighborhood centers, public parks, places of worship, etc., as they work to understand and build relationships with their community partners (Hacker, 2013; Robinson et al., 2017). For community members and local agencies, these partnerships provide an opportunity to learn research methods and relevant research done outside their local context. The following section provides an overview of the benefits of CG for the critical stakeholders described in the "Who" section above.

\section{Benefits for academic researchers}

CG allows researchers and faculty to engage in teaching and research that inherently considers notions of productive outcomes and reciprocity. Additionally, they can incorporate local knowledge and spatial reasoning in their teaching and research. Wrapped up in these more systemic answers to the question of "why" engage in CG, the approach pushes geographers to consider a wide range of approaches 
for creative problem-solving, capacity building, and accessible data sharing/communication (aacu.org, 2014). Practically, a researcher involved in CG can easily demonstrate intellectual merit and broader impacts for their projects, which often provides support in grant applications (Robinson \& Hawthorne, 2018).

\section{Benefits for university students}

As discussed in Rees et al. (2020) and Hawthorne et al. (2014), CG in the classroom is typically framed as a service-learning course where students play an integral role in formulating and carrying out research relevant to community partners. This type of engagement allows students meaningful opportunities to produce work with "real-world" impacts (Hawthorne et al., 2014; Jeavons, 1995; Yoder, 2016). CG also asks students to consider how scholarship can be used to support social change (as determined by the community), questions of in/exclusion in the production of research, and how knowledge production is influenced by multiple axes of difference (race, gender, class, culture). Additionally, the process of collaborative research allows students to develop professional skill sets, such as verbal and written communication, negotiation of time frames and expectations, and production of research materials that uphold professional standards (Hawthorne et al., 2014). Students in the NSF REU Site in Atlanta, Georgia, were asked what they liked best about the community geography REU; students mentioned: "people, the research and fieldwork, scholarly freedom, and satisfaction of community partners" (Hawthorne \& Jarrett, 2018:5).

The Community GIS and Citizen Science REU at UCF is another example of a student CG research program. Students across multiple disciplines utilize geospatial technology research skills while collaborating with community partners in Belize using GIS, participatory sketch mapping, fieldwork, communitybased uses of drones, and spatial storytelling with interviews and informal conversations to understand community concerns and future visions. US students work with University of Belize students and community partners in Hopkins Village and along the Belize barrier reef in the program. These community partners include the village council, village library, small business owners, tour guides, and local Red Cross representatives. The students from both UCF and the University of Belize work with the community partners to complete action-oriented research while developing open data tools.

Benefits for academic institutions

CG presents benefits at the departmental, disciplinary, and institutional levels as well to the individual researchers and students. In 32 Ideas to Enhance Diversity in Your Geography Department or Program (Solis \& NG, 2010), the American Association of Geographers demonstrates the importance of increasing the range and depth of perspectives within the discipline. Two of the 32 ideas included are "offering service-learning courses and projects" and "forming strategic partnerships with community organizations" at the department level, which are both central tenets of CG. More specifically, CG can support programs and the discipline by recruiting students and faculty from underrepresented backgrounds, establishing avenues for student employment, and publicizing departmental projects.

CG projects can support institutional missions; they can contribute to a university's educational mission by creating opportunities for skill development and meaningful community engagement for students and researchers (Robinson et al., 2017). Institutions across the nation are embracing what the American Association of Colleges and Universities calls high impact practices (HIPs). HIPs are reported to be incredibly supportive of students from diverse backgrounds and focus on active learning. CG engages with three of those ten HIPs, including collaborative projects, undergraduate research, and community-based learning. Additionally, an institution that supports the scholarship, research, and teaching of community geographers is likely to have a competitive application to be considered for the Elective Community Engagement Classification offered by the Carnegie Foundation.

Benefits for non-academic partners

Non-academic partners may benefit from CG partnerships by leveraging the expertise of academic researchers to support decision-making and strategic planning academic resources. These partners may also benefit by leveraging academic resources and tools to 
address community concerns and use students and faculty to assist in research projects of community interest that otherwise would be difficult or too expensive to complete. CG gives local residents and community groups ownership and power over data, analysis, and research products (Hacker, 2013). This redistribution of power can provide voice and collaborative control of project goals to underrepresented and under-resourced communities (Arnstein, 1969). Non-academic partners may also choose to partner with universities to build power by forming connections to the university or gaining respect from government bodies and other organizations with preexisting alliances with the university. Another beneficial outcome may include increased community cohesion (Ramasubramanian, 2010). Ultimately, a community or non-academic partners' beneficial outcomes from a CG project should be determined by the community groups themselves and explicitly discussed at the project's initiation with the academic research and other partners.

Focusing on one of the more tangible benefits for a community, we want to highlight how these partners may leverage the expertise of researchers, specifically in terms of data collection, analysis, and interpretation (Strand et al., 2003). Many organizations lack resources for formal evaluation (Hawthorne et al., 2014). Research collaborations can provide data demonstrating program effectiveness for funders or local residents and suggest areas where new programs may be needed for local agencies and non-profits.

A prime example of leveraging the expertise of researchers is the University of Central Florida (UCF) Citizen Science GIS program and its NSF-funded REU project in Hopkins, Belize. Results of the work are shared in a variety of formats, including printed paper maps, web maps through the newly created Hopkins Village Open Data Mapping Site, story maps, social media posts, and drone imagery flown by Hopkins Uncut (a large village tourism and cultural, social media site). As another example, in the UGA food bank study, The Stabilizing Lives Initiative, researchers from the University of Georgia and Georgia State University supported the Atlanta Community Food Bank by helping to design and evaluate the Food First Model.

\section{How}

Implementing a project relies on identifying who will be involved and why they want to be involved. These two principles of CG influence how the project will be conducted; including the project design, methods and research approach, and sharing of outcomes and project evaluation. In this section, we describe three essential elements of implementing a CG project, (1) project design: is the project initiated by the community partners or the academics, who is leading, and how are the partnerships being managed? (2) methods and research approach: how will the work be performed? (3) sharing outcomes: open research and project evaluation.

\section{Project design}

Who is involved in a CG project and why they are involved directly influences the project design and how it is initiated. There are many examples of project design, including two key ends of the spectrum, along with variations in between these spectrums: (a) more grassroots (the community partner initiates a project and approaches the researcher or the research team for assistance) or (b) more top-down where the researcher or research team asks the community for assistance to address specific research questions. Various frameworks exist to describe this spectrum of projects (including Shirk, 2012 and Hakaly, 2012). As an example, we will highlight the framework presented in Shirk et al. (2012). This framework offers a model of modes of engagement, including (1) contractual projects, where communities ask professional researchers to conduct specific research and report on the results; (2) contributory projects, which are generally designed by researchers and for which members of the public primarily contribute data; (3) collaborative projects, which are typically designed by researchers and for which members of the community contribute data, but also help to refine project design, analyze data, and/or disseminate findings; (4) cocreated projects, which are designed by researchers and members of the public working together and for which at least some of the community participants are actively involved in most or all aspects of the research process; and (5) collegial contributions, where noncredentialed individuals conduct research independently with varying degrees of expected recognition 
by institutionalized science and professionals. CG builds upon Shirk et al.'s model by adding one additional mode of engagement where a community initiates the project and approaches a researcher with their own goals, outputs, and outcomes in mind.

\section{Practicalities of project design and initiation: external funding}

Another element of initiating a project is funding. Fortunately, as agencies like NSF increasingly expect "broader impacts" of research to connect with and benefit broader society, there have been more funding opportunities for community-engaged research. The NSF, for example, has funded two REU Sites explicitly focused on CG. Funded in 2011, an REU Site led by Timothy Hawthorne and Katherine Hankins at Georgia State University (GSU) focused on CG approaches to exploring urban greenspace, neighborhood gentrification, environmental contaminants, and food justice issues in Atlanta, GA neighborhoods. In 2016, the Belize REU site mentioned above, led by Timothy Hawthorne at UCF and Christy Visaggi at GSU, was funded and has been renewed in 2020 for three more years with Hawthorne and Hannah Torres at George Mason University, along with an additional Research Experiences for Teachers (RET) component to acknowledge K-12 interests in community geography. Recently, NSF also funded a conference grant led by Jerry Shannon at UGA and additional CG collaborators to support the nation's first workshop of community geographers (January 2019) in Atlanta at GSU. In some cases, community partners may also play a key role in securing funding. At UGA, a project on affordable housing in rural Georgia relies on support from the state Department of Community Affairs as communities analyze data on local housing conditions and assess the match with available state and federal programs.

\section{Practicalities project design and initiation: formal partnership agreements}

Agreements between CG partners may include a formal memorandum of understanding (MOU), Institutional Review Board (IRB) approval, and/or an ethics statement (IRB approval is discussed in more detail in Sect. 4.2.5). The type of agreement is determined by the expected duration and complexity of the partnership. As an example, CG centers handle short-term partnerships in a variety of ways. At Chicago State, a small project such as a single map might be completed without a formal agreement or request. On the other hand, Syracuse Community Geography has an online form to request assistance and a board that helps decide which projects are adopted and employs a more formal process of developing agreements with community partners. An ethics statement may be a required piece of a formal agreement between partners. These statements should consider the whole life of a project even after the research is conducted. Ethics statements with diverse partners can promote trust, accountability, mutual respect, and fairness; these values are essential in collaborative work.

Research approaches and methods

CG includes a diversity of methods and research approaches used for research and the implementation of programs. Shannon et al. (2020) point to this diversity in methodology and research approach as a key characteristic of CG. Robinson et al. (2017) and Hawthorne et al. (2014) also point to the variety of CG methods and the flexibility of these methods to fit the research questions and goals of a project. This section provides an overview of common research methodologies and approaches commonly used in CG programs and references to papers and other resources that can provide more in-depth details and backgrounds on these methods.

\section{PPGIS/PGIS}

Public participation in geographic information systems (PPGIS) and participatory GIS (PGIS) first emerged as research methodologies in the late 1990s (Pickles, 1995; Schuurman, 2000; Sieber, 2006; Weiner et al., 2002). Elwood and Ghose (2001) define it generally as "grassroots community involvement in knowledge production through GIS analysis and in the application of knowledge produced" (p. 19). PPGIS and PGIS are broadly similar and sometimes combined, but some have noted that PPGIS is more policyfocused and common in the global north. At the same time, PGIS is often used in the global south and focused on representing indigenous knowledges (Brown \& Kyttä, 2014). 
In practice, research in PPGIS has focused on both the research process and on developing methods for public participation. Ghose's (2007) study of the use of GIS by neighborhood groups in Milwaukee, for example, finds that some groups made use of GIS to gain political traction but also that, while flexible, the new networks created by these groups remained uneven and hierarchical. Empirically, PPGIS has relied on multiple tools to solicit community participation and input, including sketch mapping (Boschmann \& Cubbon, 2014; Cinderby, 2010; Pearsall et al., 2015) tools for digital data collection (Brovelli et al., 2016; Verplanke et al., 2016) and online visualization tools (Hall et al., 2010; Shannon \& Walker, 2018).

PPGIS is a common methodology within CG (Robinson et al., 2017) due to its methodological focus on cooperative research and community empowerment. For many non-academic communities, PPGIS provides tangible results with immediate relevance: new data or maps used for advocacy, publicity, or funding applications (Boll-Bosse \& Hankins, 2018; Case \& Hawthorne, 2013). For most authors of this article, mapping is one of the primary tasks community partners are interested in when discussing potential collaborations. It can provide a pathway into other mixed-methods research.

\section{VGI/citizen science}

Data and STEM-centric participatory research include Volunteered Geographic Information (VGI) and citizen science programs. VGI is an umbrella term that captures a spectrum of data produced by the public. This can range from passive to active production of geographic data by the public (Haklay, 2013). For instance, geo-tagged tweets and the concept of citizens-as-sensors is passive VGI collection. On the other end of the spectrum, a citizen science project involving volunteers in data collection is active participation. The term VGI was coined in 2007 by Michael Goodchild, who describes VGI as the engagement of private citizens to create geographical information (Goodchild, 2007).

Citizen science is the act of public volunteers participating in a scientific research project, usually through data collection, but in some cases, project development or data analysis, etc. (Haklay, 2013). These projects exist across disciplines, including ecology, environmental sciences, earth science, health, astronomy, and geography (Bonney et al., 2014; Silvertown, 2009). When these programs are collecting or analyzing spatial data, these data can be considered VGI. Citizen science programs often include volunteers and scientific outcomes; volunteer outcomes include some benefits to the volunteers or local community in the study area; this may be a positive learning experience. Scientific outcomes may consist of data, data analysis, or something that contributes to the research being conducted in the project (Wiggins et al., 2018). The Citizen Science GIS group at the University of Central Florida, led by Timothy Hawthorne, positions itself in the realm of citizen science because they collect life and physical science data along with social science data in Belize, Florida, and the US Pacific Coast with community partners and agencies.

\section{$P A R / C B P R$}

Participatory Action Research (PAR) and Community-Based Participatory Research (CBPR) are participatory research approaches that influence many $\mathrm{CG}$ research projects and collaborations. Both developed as responses to the traditional research model that seeks to separate researchers from research subjects and often results in research focusing on the extraction of information rather than assisting communities in need. PAR is an action-based framework that originated primarily within the social sciences and was initially promoted by Freire (2000). In Brazil in the 1960s and 1970s, Freire used PAR type approaches to help oppressed people participate in knowledge production and social transformation. He encouraged poor and deprived communities to examine and analyze the structural reasons for their oppression (Baum et al., 2006: Freire, 2000; Kindon et al., 2007). PAR involves a deep engagement between community activists and researchers towards a goal of co-producing research findings that are relevant and actionable to both parties (Kindon \& Elwood, 2009). Ideally, PAR leads to a series of actions and reflections where researchers and community activists establish relationships, set project roles, research questions, complete the research analysis, and carry out actions resulting from the projects. It has been utilized in geography projects involving subjects from street youth in Colombia (Ritterbusch, 2012) to an environmental study of British watersheds (Whitman et al., 
2015). It can also be used as a framework for servicelearning projects in a classroom setting (Pain et al., 2013).

In practice, PAR is challenging to fulfill, as researchers may often set the original research focus, or community partners may not have time to participate in each step. However, even approaching these goals can significantly enhance the usefulness of the outcomes to the community (Klocker, 2012). Mason (2015) and Ritterbusch (2012) suggest that an "ethics of care" be used in PAR collaborations, focusing on the development of caring connections and friendships between researchers, community activists, and research subjects, rather than the "ethics of justice" that is a basis of most human subject protection systems.

Community-Based Participatory Research (CBPR) stem from the Health Sciences and has been led by Barbara Israel and colleagues at the Detroit Urban Research Center, a community-based research center affiliated with the University of Michigan, and (along with similar centers in New York and Seattle) supported by the Centers for Disease Control (Israel et al., 2006). Like PAR, CBPR is not a defined methodology but a set of steps meant to ensure community participation in research. These steps include community participation in developing research questions, completing research and analysis, and writing papers, reports, and grant proposals. Geographers working in medical geography have utilized CPBR methods, often within the context of community-based GIS work on medical or public health projects (Block \& Kouba, 2006). Koster et al. (2012) and Castleden et al. (2012) both utilize CBPR methods for non-medical geography projects involving indigenous peoples in Canada.

\section{Mixing methods and approaches}

The focus on flexible epistemologies in CG research results in projects that often take a mixed-methods (qualitative and quantitative methods) approach; this can include multi-stage projects, where interviews with community members suggest frameworks for GIS-based analysis, or explicitly mixed-methods techniques such as sketch mapping (Boschmann \& Cubbon, 2014) and Q sorts (Hawthorne et al., 2008; Sneegas, 2019). Knigge and Cope (2006) present' grounded visualization', a particularly significant mixed-methods framework for combining traditional GIS-based spatial data and multimedia formats of qualitative data such as interviews, images, sketches, and audio and video files and analyze these various forms of data through an iterative and reflective qualitative analysis based on the grounded theory. Grounded visualization integrates geographic visualization with ethnographic research to draw out interpretative meanings and theorize socio-spatial processes and politics in the community.

At UGA, one community-based project with a local biking organization used sketch mapping to discuss the safest and most dangerous routes in the city. Working from a blank sheet of paper, individuals drew their daily routes and used highlighters to mark their perceived levels of safety. The resulting maps were later digitized, but the transcribed conversation about these maps was just as valuable in highlighting key issues affecting bike safety. Similarly, in collaboration with the Atlanta food bank, researchers used photographs as a focal point for both individual interviews and concept mapping. The former were coded using qualitative analysis software to identify key obstacles faced by food pantry clients, while the latter used clustering analysis to group photos with common themes (Kurtz et al., 2019).

\section{Practicalities of methodologies and research approaches: institutional review board considerations}

If human subjects research is included in the project, the research protocol would need to be reviewed and approved by the Institutional Review Board (IRB) at the lead researcher's institution or a third-party review board. As has been pointed out by Tamariz et al. (2015) and others, community-based projects often have difficulty with the IRB approval process. IRB boards are often unfamiliar with community-based research. IRB policies also view research as being completed or led by an academic or medical researcher and the community as the subject. IRB's tend to have difficulty with cases in which the community organizations are actually part of the research team, helping create measures and collect and analyze data.

An alternative to a university-based IRB is a Community IRB or Community Research Review Board (Carroll-Scott, 2020). In the US, these have been set up as non-profit entities in many US cities and 
are community-controlled IRB boards that specifically focus on community-based research. Some replace traditional IRB's while others provide an alternate research ethics determination or work to protect the community, in addition to individual rights in conjunction with university IRB's.

Sharing outcomes: open research and project evaluation

\section{Open research and its benefits}

Open research is a key characteristic of CG and often a key research outcome for both the academics and the community. CG often borrows from ongoing work toward open science practices and open data initiatives favoring open source technologies (Shannon \& Walker, 2018; Sieber \& Johnson, 2015). Many governmental agencies have created online data portals using platforms such as Socrata or Esri's ArcGIS Hub (Johnson \& Sieber, 2013; Sieber \& Johnson, 2015). These portals intend to promote public transparency and enable "civic hacking" by residents and community organizations (Perng \& Kitchin, 2018). In addition to these resources, progressive social change using open data resources relies on intentional and intensive engagement with key actors (Brandusescu et al., 2016). For community geographers, the task is not merely to make data public or create technically sophisticated dashboards for exploratory analysis. Instead, the goal is to assist socially marginalized groups as they make use of, add to, or critique open data, recognizing this as one aspect of broader community organizing efforts. Simultaneously, recognizing that open data are not inherently accessible, CG advocates for using online communication or arts-based approaches to communicating research methods and results with community partners (Derickson \& Routledge, 2015).

Research in CG often focuses on locally specific issues. Still, the methodological approaches and research tools used in this work can have broader applicability. Given the ready availability of website building tools for hosting research materials, the underlying principles of open science are also applicable to mixed-methods community-based research (Singleton et al., 2016). By providing publicly available resources detailing their methodology, community geographers can support the reuse and adaptation of their research. Online repositories such as SocArXiv (https://socopen.org) and Github provide platforms for public sharing of research materials and, when possible, research data. When possible, using free and/or open-source tools also makes replication of research more possible in communities without the financial resources for proprietary software licenses.

\section{Project evaluation}

Given the many interlocking groups and priorities within a CG project, project evaluation is a critical tool for achieving successful outcomes and sharing and reflecting on these outcomes. Evaluations help determine if the project as a whole and the partners included are producing desired outcomes and support the project partners in considering how to improve a project (Davidson, 2005). Evaluation can be completed through an internal team and short surveys or contracting with an outside evaluator to perform formative, summative, or developmental evaluation (Block et al., 2018; Hawthorne \& Jarrett, 2018). There are many resources available on project evaluation, such as Michael Quinn Patton's Developmental Evaluation (2010), Russ-Eft and Preskill Evaluation in Organizations (2009), and the many other resources available online through the American Evaluation Association, as well as the Citizen Science Association's Research and Evaluation Working Group.

\section{Additional considerations when doing community geography}

Researchers and academic institutions who decide to participate in a CG project must keep in mind that the community partners they work with are, in fact, true partners in the project. There are shared outcomes for all the individuals and groups involved in the program; research and academic focused outcomes are only one of many benefits from a CG project. Forming these relationships takes time, and unfortunately, some projects do not continue or work out, funding gets cut, or researchers change positions or institutions.

CG projects can be useful to both the community members and organizations and the academic students and researchers involved despite these issues. In this paper, we presented three overarching principles of doing CG (1) who, (2) why, and (3) how; all these are 
essential concepts to consider when developing, implementing, and sustaining a CG project. The examples given here are not exhaustive as community geography continues to grow as a subfield. Yet, they serve as guiding examples for those pursuing community-focused, participatory research.

This paper was written as a basic guide to introducing academic researchers to CG. We hope that more researchers engage in $\mathrm{CG}$ and more synergies with other research approaches occur through this paper. We also hope this paper and the others in this writing project contribute to CG being more legitimately developed and recognized as a fruitful educational and research program at academic institutions. Additionally, for the benefit of community groups and non-academic partners engaging in CG with academics and academic institutions, we anticipate that this paper will lead to additional papers and resources to be developed with other CG stakeholders in mind, such as a similar practical guide to community groups engaging in community geography.

\section{Declaration}

Conflict of interest The authors declare that they have no conflict of interest.

Open Access This article is licensed under a Creative Commons Attribution 4.0 International License, which permits use, sharing, adaptation, distribution and reproduction in any medium or format, as long as you give appropriate credit to the original author(s) and the source, provide a link to the Creative Commons licence, and indicate if changes were made. The images or other third party material in this article are included in the article's Creative Commons licence, unless indicated otherwise in a credit line to the material. If material is not included in the article's Creative Commons licence and your intended use is not permitted by statutory regulation or exceeds the permitted use, you will need to obtain permission directly from the copyright holder. To view a copy of this licence, visit http://creativecommons.org/licenses/by/4.0/.

\section{References}

aacu.org. (2014). High-impact educational practices [WWW Document]. Association of American colleges \& universities. https://www.aacu.org/leap/hips. Accessed 13 Jan 2020.

Arnstein, S. R. (1969). A ladder of citizen participation. Journal of the American Institute of Planners, 35, 216-224. https:// doi.org/10.1080/01944366908977225
Baum, F., MacDougall, C., \& Smith, D. (2006). Participatory action research. Journal of Epidemiology and Community Health, 60(10), 854-857. https://doi.org/10.1136/jech. 2004.028662

Block, D., \& Kouba, J. (2006). A comparison of the availability and affordability of a market basket in two communities in the Chicago area. Public Health Nutrition, 9, 837-845.

Block, D. R., Hague, E., Curran, W., \& Rosing, H. (2018). Measuring community and university impacts of critical civic geography: Insights from Chicago. The Professional Geographer, 70, 284-290.

Boll-Bosse, A. J., \& Hankins, K. B. (2018). “These maps talk for us:" Participatory action mapping as civic engagement practice. The Professional Geographer, 70, 319-326.

Bonney, R., Shirk, J. L., Phillips, T. B., Wiggins, A., Ballard, H. L., Miller-rushing, A. J., \& Parrish, J. K. (2014). Next steps for citizen science. Science, 343, 1436-1437. https://doi. org/10.1126/science. 1251554

Boschmann, E. E., \& Cubbon, E. (2014). Sketch maps and qualitative GIS: Using cartographies of individual spatial narratives in geographic research. The Professional Geographer, 66, 236-248.

Brandusescu, A., Sieber, R. E., \& Jochems, S. (2016). Confronting the hype: The use of crisis mapping for community development. Convergence, 22, 616-632.

Breen, J., Dosemagen, S., Warren, J., \& Lippincott, M. (2015). Mapping grassroots: Geodata and the structure of community-led open environmental science. ACME, 13(3), 849-873.

Brovelli, M. A., Minghini, M., \& Zamboni, G. (2016). Public participation in GIS via mobile applications. ISPRS Journal of Photogrammetry and Remote Sensing, 114, 306-315.

Brown, G., \& Kyttä, M. (2014). Key issues and research priorities for public participation GIS (PPGIS): A synthesis based on empirical research. Applied Geography, 46, 122-136.

Carroll-Scott, A., (2020). Importance of a place-based and community-moderated system of research oversight to maximize benefits for social change. Social Innovations Journal, 2.

Case, C., \& Hawthorne, T. L. (2013). Served or unserved? A site suitability analysis of social services in Atlanta, Georgia using geographic information systems. Applied Geography, 38, 96-106.

Castleden, H., Morgan, V. S., \& Lamb, C. (2012). "I spent the first year drinking tea": Exploring Canadian university researchers' perspectives on community-based participatory research involving indigenous peoples. The Canadian Geographer/le Géographe Canadien, 56, 160-179.

Cinderby, S. (2010). How to reach the 'hard-to-reach': The development of participatory geographic information systems (P-GIS) for inclusive urban design in UK cities. Area, 42, 239-251.

Davidson, E. J. (2005). Evaluation methodology basics: The nuts and bolts of sound evaluation. Sage.

Derickson, K. D., \& Routledge, P. (2015). Resourcing scholaractivism: Collaboration, transformation, and the production of knowledge. The Professional Geographer, 67, 1-7.

Dewey, J. (2016). The public and its problems: An essay in political inquiry. Swallow Press. 
Eaves, L. E. (2017). Black geographic possibilities. Southeastern Geographer, 57(1), 80-95.

Elwood, S. (2006). Critical issues in participatory GIS: Deconstructions, reconstructions, and new research directions. Transactions in GIS, 10(5), 693-708.

Elwood, S., \& Ghose, R. (2001). PPGIS in community development planning: Framing the organizational context. Cartographica The International Journal for Geographic Information and Geovisualization, 38(3-4), 19-33.

Freire, P. (2000). Pedagogy of the oppressed. Continuum.

Ghose, R. (2007). Politics of scale and networks of association in public participation GIS. Environment and Planning A, 39(8), 1961-1980.

Goldstein, J. E., Paprocki, K., \& Osborne, T. (2019). A manifesto for a progressive land-grant mission in an authoritarian populist era. Annals of the American Association of Geographers. https://doi.org/10.1080/24694452.2018. 1539648

Goodchild, M. F. M. (2007). Citizens as sensors: The world of volunteered geography. GeoJournal, 69, 211-221.

Hacker, K. (2013). Community-based participatory research. Sage Publications.

Haklay, M. (2013). Citizen science and volunteered geographic information: Overview and typology of participation. Crowdsourcing Geographic Knowledge, 105-122.

Hall, G. B., Chipeniuk, R., Feick, R. D., Leahy, M. G., \& Deparday, V. (2010). Community-based production of geographic information using open source software and web 2.0. International Journal of Geographical Information Science, 24, 761-781.

Haraway, D. (1988). Situated knowledges: The science question in feminism and the privilege of partial perspective. Feminist Studies, 14(3), 575-599.

Harney, L., McCurry, J., Scott, J., \& Wills, J. (2016). Developing "process pragmatism" to underpin engaged research in human geography. Progress in Human Geography. https://doi.org/10.1177/0309132515623367

Hawthorne, T. L., \& Jarrett, O. S. (2018). Developing the next generation of community-based scholars. The Professional Geographer, 70, 291-297.

Hawthorne, T., Krygier, J., \& Kwan, M. P. (2008). Mapping ambivalence: Exploring the geographies of community change and rails-to-trails development using photo-based Q method and PPGIS. Geoforum, 39(2), 1058-1078.

Hawthorne, T. L., Atchison, C., \& LangBruttig, A. (2014). Community geography as a model for international research experiences in study abroad programs. Journal of Geography in Higher Education, 38, 219-237. https://doi. org/10.1080/03098265.2014.908351

Hawthorne, T. L., Solís, P., Terry, B., Price, M., \& Atchison, C. L. (2015). Critical reflection mapping as a hybrid methodology for examining sociospatial perceptions of new research sites. Annals of the Association of American Geographers, 105(1), 22-47.

High country news, (2020). https://www.hcn.org/issues/52.4/ indigenous-affairs-education-land-grab-universities.

Israel, B. A., Krieger, J., Vlahov, D., Ciske, S., Foley, M., Fortin, P., Guzman, J. R., Lichtenstein, R., McGranaghan, R., \& Palermo, A. (2006). Challenges and facilitating factors in sustaining community-based participatory research partnerships: Lessons learned from the Detroit, New York city and Seattle urban research centers. Journal of Urban Health, 83, 1022-1040.

Jeavons, T. H. (1995). Service-learning and liberal learning: A marriage of convenience. Michigan Journal of Community Service Learning, 2, 134-140.

Johnson, P. A., \& Sieber, R. E. (2013). Situating the adoption of VGI by government. Crowdsourcing geographic knowledge (pp. 65-81). Springer.

Kindon, S., \& Elwood, S. (2009). Introduction: More than methods-reflections on participatory action research in geographic teaching, learning and research. Journal of Geography in Higher Education, 33(1), 19-32.

Kindon, S., Pain, R., \& Kesby, M. (Eds.). (2007). Participatory action research approaches and methods: Connecting people, participation and place (Vol. 22). Routledge.

Klocker, N. (2012). Doing participatory action research and doing a $\mathrm{PhD}$ : Words of encouragement for prospective students. Journal of Geography in Higher Education, 36, 149-163.

Knigge, L., \& Cope, M. (2006). Grounded visualization: Integrating the analysis of qualitative and quantitative data through grounded theory and visualization. Environment and Planning A, 38, 2021-2037.

Koster, H. R., van Ommeren, J., \& Rietveld, P. (2012). Bombs, boundaries and buildings: A regression-discontinuity approach to measure costs of housing supply restrictions. Regional Science and Urban Economics, 42, 631-641.

Kurtz, H., Borron, A., Shannon, J., \& Weaver, A. (2019). Community food assistance, informal social networks, and the labor of care. Agriculture and Human Values, 36(3), 495-505.

Mason, K. (2015). Participatory action research: Coproduction, governance and care. Geography Compass, 9(9), 497-507.

McTaggart, R. (1991). Principles for participatory action research. Adult Education Quarterly, 41(3), 168-187.

National Science Foundation (US). (2007). Proposal and award policies and procedures guide: Award \& administration guidelines. National Science Foundation.

Pain, R., Finn, M., Bouveng, R., \& Ngobe, G. (2013). Productive tensions-engaging geography students in participatory action research with communities. Journal of Geography in Higher Education, 37, 28-43.

Patton, M. Q. (2010). Developmental evaluation: Applying complexity concepts to enhance innovation and use. Guilford Press.

Pavlovskaya, M., \& St. Martin, K. (2007). Feminism and geographic information systems: From a missing object to a mapping subject. Geography Compass, 1(3), 583-606. https://doi.org/10.1111/j.1749-8198.2007.00028.x

Pearsall, H., Hawthorne, T., Block, D., Walker, B. L. E., \& Masucci, M. (2015). Exploring youth socio-spatial perceptions of higher education landscapes through sketch maps. Journal of Geography in Higher Education, 39, 111-130.

Perng, S.-Y., \& Kitchin, R. (2018). Solutions and frictions in civic hacking: Collaboratively designing and building wait time predictions for an immigration office. Social and Cultural Geography, 19, 1-20.

Pickles, J. (1995). Ground truth: The social implications of geographic information systems. Guilford Press. 
Ramasubramanian, L. (2010). Geographic information science and public participation. Springer Science \& Business Media.

Rees, A., Hawthorne, T., Scott, D., (2020). Teaching community geography: Partnership, process, reciprocity, and reflection, and communication. Journal of Geography, 1-12. https://doi.org/10.1080/00221341.2020.1841820.

Ritterbusch, A. (2012). Bridging guidelines and practice: Toward a grounded care ethics in youth participatory action research. The Professional Geographer, 64, 16-24.

Robinson, J. A. (2010). Syracuse Community Geography: Evaluating a New Approach to Public Participation Geographic Information Systems. https://doi.org/10.17615/ h2ee-pj75

Robinson, J. A., \& Hawthorne, T. L. (2018). Making space for community-engaged scholarship in geography. The Professional Geographer, 70, 277-283.

Robinson, J. A., Block, D., \& Rees, A. (2017). Community geography: Addressing barriers in public participation GIS. The Cartographic Journal, 54, 5-13.

Russ-Eft, D., \& Preskill, H. (2009). Evaluation in organizations: A systematic approach to enhancing learning, performance, and change. Basic Books.

Schuurman, N. (2000). Trouble in the heartland: GIS and its critics in the 1990s. Progress in Human Geography, 24, 569-590.

Shannon, J., \& Walker, K. (2018). Opening giscience: A process-based approach. International Journal of Geographical Information Science, 32, 1911-1926.

Shannon, J., Borron, A., Kurtz, H. E., Weaver, A., Otto-Wang, S., \& Gilliam, V. (2019). Translating across registers: Pragmatist inquiry in engaged scholarship. Journal of Higher Education Outreach and Engagement, 23, 36-50.

Shannon, J., Hankins, K., Shelton, T., Bosse, A., Scott, D., Block, D., Fischer, H., Eaves, L., Jung, J.-K., Robinson, J., Solis, P., Pearsall, H., \& Nicolas, A. (2020). Community geography: Toward a disciplinary framework. Progress in Human Geography. https://doi.org/10.1177/ 0309132520961468

Shirk, J. L., Ballard, H. L., Wilderman, C. C., Phillips, T., Wiggins, A., Jordan, R., \& McCallie, E. (2012). Public participation in scientific research: A framework for intentional design. Ecology and Society, 17(2), 29-29.

Sieber, R. (2006). Public participation geographic information systems: A literature review and framework. Annals of the Association of American Geographers, 96, 491-507.
Sieber, R. E., \& Johnson, P. A. (2015). Civic open data at a crossroads: Dominant models and current challenges. Government Information Quarterly, 32, 308-315.

Silvertown, J. (2009). A new dawn for citizen science. Trends in Ecology \& Evolution, 24(9), 467-471.

Singleton, A. D., Spielman, S., \& Brunsdon, C. (2016). Establishing a framework for open geographic information science. International Journal of Geographical Information Science, 30, 1507-1521.

Sneegas, G. (2019). Making the case for critical Q methodology. The Professional Geographer. https://doi.org/10.1080/ 00330124.2019.1598271

Solis, P., NG, A., (2010). 32 things to enhance diversity in your geography program or department. [WWW Document]. URL http://www.aag.org/cs/programs/diversity/aligned/ 32ideas. Accessed 13 Jan 2020.

Strand, K. J., Cutforth, N., Stoecker, R., Marullo, S., \& Donohue, P. (2003). Community-based research and higher education: Principles and practices. John Wiley \& Sons.

Tamariz, L., Medina, H., Taylor, J., Carrasquillo, O., Kobetz, E., \& Palacio, A. (2015). Are research ethics committees prepared for community-based participatory research? Journal of Empirical Research on Human Research Ethics, 10, 488-495.

Verplanke, J., McCall, M. K., Uberhuaga, C., Rambaldi, G., \& Haklay, M. (2016). A shared perspective for PGIS and VGI. The Cartographic Journal, 53, 308-317.

Weiner, D., Harris, T. M., \& Craig, W. J. (2002). Community participation and geographic information systems. CRC Press.

Whitman, G. P., Pain, R., \& Milledge, D. G. (2015). Going with the flow? Using participatory action research in physical geography. Progress in Physical Geography, 39, 622-639.

Wiggins, A., Bonney, R., LeBuhn, G., Parrish, J. K., \& Weltzin, J. F. (2018). A science products inventory for citizen-science planning and evaluation. BioScience, 68(6), 436-444.

Wills, J., \& Lake, R. W. (2020). Introduction: The power of pragmatism. In J. Wills \& R. W. Lake (Eds.), The power of pragmatism (pp. 3-52). Manchester University Press.

Yoder, S. D. (2016). Pragmatism, pedagogy, and community service learning. Michigan Journal of Community Service Learning, 22, 5-15.

Publisher's Note Springer Nature remains neutral with regard to jurisdictional claims in published maps and institutional affiliations. 